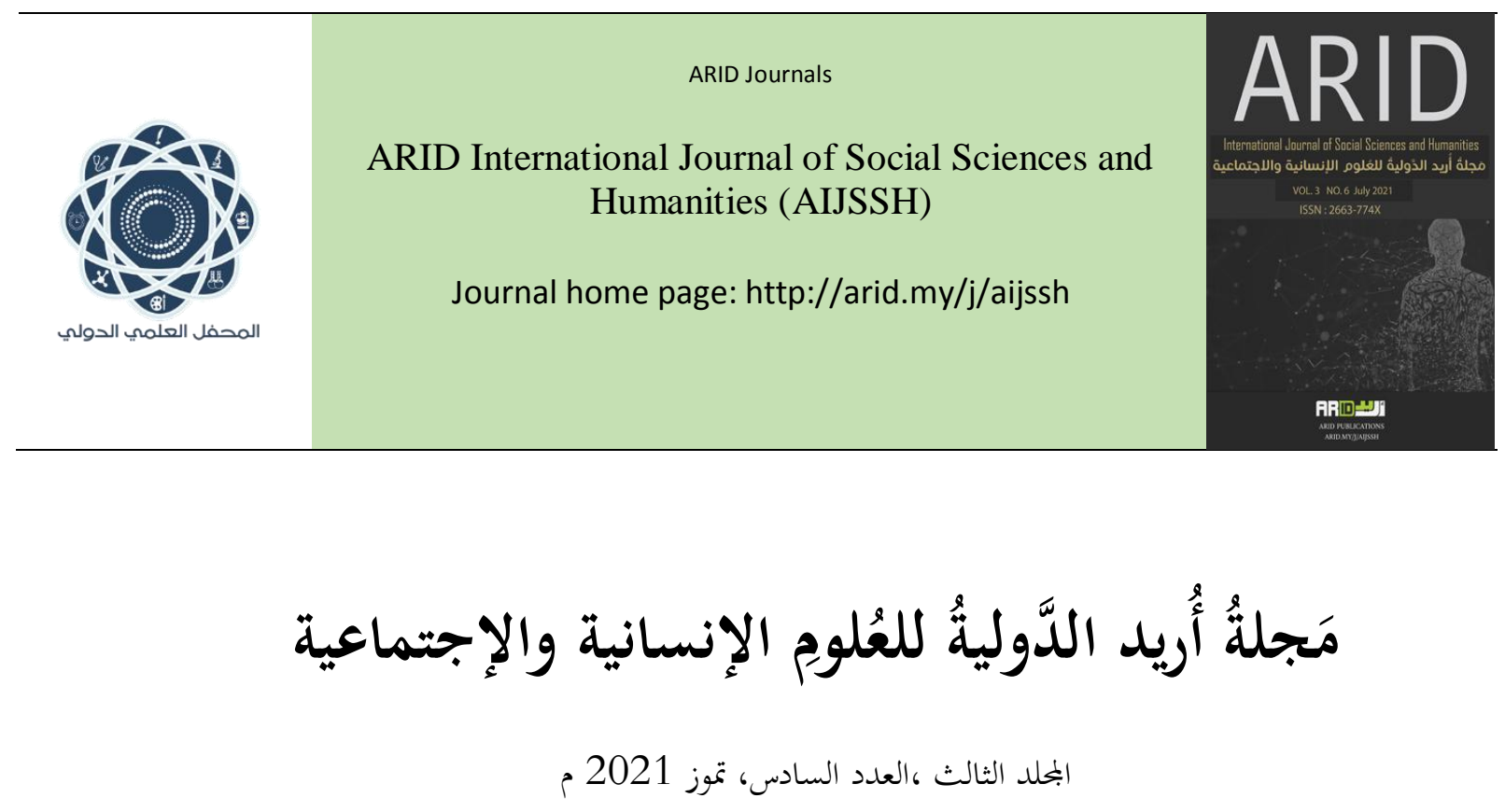

\title{
Parties and civil Society Organization in Libya Political Life
}

\author{
Elyas Abobaker.A. Elbarouni
}

Faculty of Low and Political Since, University of Nalut

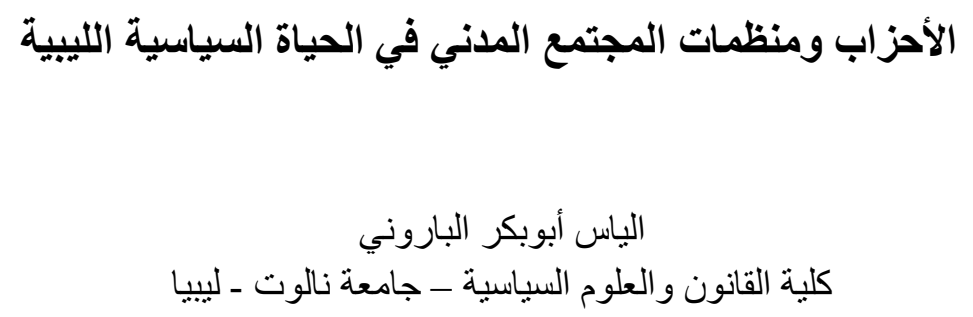




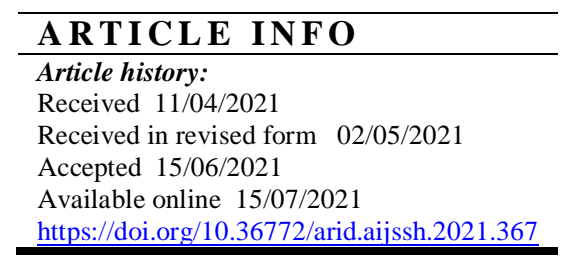

\begin{abstract}
There is no doubt that the Libyan society is rich in its demographic and socio-cultural composition, but it was not accompanied by an effective and influential civil society. The tribe was the main controlling factor in the political arena through its political exploitation, especially during the period of Colonel Gaddafi's rule, Rejecting every political color under the pretext of "Who demonstrates other Islamic and civil parties , betrays," and "the partisan abortion of democracy," and the representation of the representation of the "and other political armaments abhorrent, a ranking of the aforementioned is the problem statement of the President's question of: What is the nature of the role of parties and civil society organizations in political life?. The study aims to identify the emergence of political parties in Libya, clarifying the map of the Islamic parties involved in Libyan political life, and then highlighting the role of civil parties in Libyan political life, as well as standing in the reality of civil society organizations in Libyan political life. The study is a descriptive, descriptive method and a critical analytical approach to understand, study, describe and analyze the role of political parties and civil society organizations and their tools in shaping the political system of Libya, reaching the most important results which was recently created for the first time after the fall of Gaddafi reflected a competitive dynamic, but still lacks the ability to declare specific political programs and identify their political identity and position on current issues related to development issues that Libya seeks to achieve. Following the Libyan revolution in February, a large number of civil society institutions and organizations But it is still limited in activity and there is no presence in all regions of Libya, which reflects the initiative and seek to control the formation of gatherings and federations without having a practical translation at the grassroots level throughout the country.
\end{abstract}

Keywords: role-parties-civil society organizations-Libyan political life-Islamic and civil currents. 
الملخص

لا شك أن المجتمع الليبي غني بتركيبته الديموغر افية والسوسيوثقافية ولكنه لم يواكب مجتمع مدني فاعل ومؤثر؛ فالقبيلة كانت المتحكم الأساسي في المعترك السياسي من خلال توظيفها سياسيًا خصوصًا في مرحلة حكم العقيد "القذافي" الذي عمل على "تصحير" الحياة السياسية، وحقنها بأيديولوجيا "رمادية" ترفض كل لون سياسي بدعوى "من تحزّب خان"، و "الحزبية إجهاض للايمقر اطية"، و التمنيل النيابي تدجيل"، وغير ها من الأذرع السياسية الأيديولوجية المقيتة، ترتيبا مما سبق تتركز إثكالية الدراسة على سؤال رئيس المتمثل في:

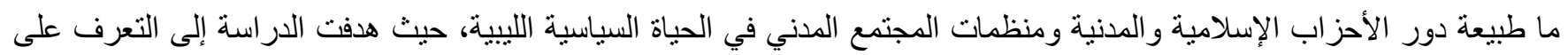
نشأة الأحز اب السياسية في ليبيا، وتوضيح خريطة الأحزاب الإسلامية المنخرطة في الحياة السياسية الليبية، ومن ثم محاولة إبراز دور الأحزاب المدنية في الحياة السياسية الليبية، وكذلك الوقوف عند واقع منظمات المجتمع المدني في الحياة السياسية اللايبية، واستخدمت لإني الدراسة المنهج الاستقرائي الوصفي، والمنهج التحليلي النقدي، وذلك لفهم ودراسة ووصف وتحليل دور الأحزاب السياسية ومنظمات

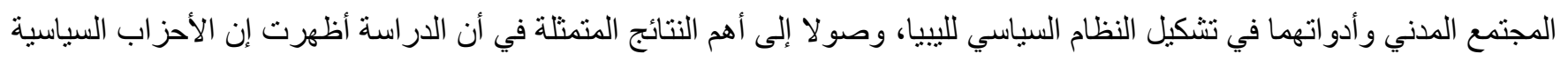
التي نشأت حديثا لأول مرة عقب سقوط القذافي عكست دينامية تنافسية، ولكنها لا تز ال تفتقر إلى القدرة على إعلان بر امج سياسية محددة و تحديد هويتها السياسية وموقفها من القضايا الر اهنة المتعلقة بقضايا التنمية التي تسعى ليبيا لتحقيقها، و عقب ثورة فبراير اللبيية تم تشكيل عدد كبير من مؤسسات ومنظمات المجتمع المدني لكنها لا تز ال محدودة النشاط و لا يوجد نو اجد لها في كل مناطق ليبيا، وهو ما يعكس أسلوب المبادرة والسعي إلى السيطرة بتكوين تجمعات و اتحادات بدون أن يكون لها ترجمة عملية على المستوى الشعبي في كل أرجاء

كلمات مفتاحية: دور ـ الأحزاب ـ منظمات المجتمع المدني ـ الحياة السياسية الليبية ـ التيار ات الإسلامية و المدنية. 
حظر نظام حكم القذافي الأحز اب السياسية وأعتبر تكوينها جريمة عقوبتها الإعدام (القانون رقم (71) لسنة 1972، أما النقابات والروابط المهنية الجماعية فكان لز اما عليها الالتزام بالسياسة العامة للدولة التي تملك وحدها حق إنثاء أو حل هذه التنظيمات [1]. و عقب ثورة فبراير الليبية 2011 تم تنكيل عدد كبير من مؤسسات ومنظمات المجتمع المدني لكنها لا تزال محدودة النشاطو لا يوجد تو اجد لها في كل مناطق ليييا، وهو ما يعكس أسلوب المبادرة والسعي إلى السيطرة بنكوين تجمعات واتحادات بدون أن يكون لها ترجمة عملية على المستوى الثعبي في كل أرجاء البلاد. من خلال ما تقدم تناولت الدر اسة أربعة مباحث شملت نشأة الأحزاب السياسية في ليييا، وخريطة الأحزاب الإسلامية المنخرطة في الحياة السياسية الليبية، وتطرقت إلى الأحزاب الدننية ودور ها في الحياة السياسية الليبية، وأخيرا قدمت واقع منظمات الدجمع الددني في الحياة السياسية الليبية.

\section{مشكلة الاراسة:}

ذللك أن نجاح الثورة فتح الباب على مصر اعيه أمام كل الليبيين، ومن ثم بدأت قوى سياسية مختلفة في التعبير عن نفسها بأنشكال وتعبير ات أو تمثلات متعدّدة بو لادة أشكال ومستويات مختلفة، وتم الإعلان عن تأسيس تنظيمات غير رسمية بشكل غير مسبوق في تاريخ الثعب الليبي الحديث والمعاصر، ومن أبرز ها تأسيس الأحزاب السياسية وتنظيمات المجتمع المدني، الذي يتعين عليهما مهام جسام تتمثل في محاربة "تسييس" عمل المجتمع المدني، والعمل على ترقية المجتمع المدني في مجال محاربة الفساد وتعزيز الثفافية نحو تحقيق تتمية سياسية في المجتمع الليبي [2]، وترتيبا على ما سبق تتركز إنكالية الدر اسة على سؤال مركزي متمثل في: مـا طبيعة دور الأحز اب الإسلامية و المدنية ومنظمات المجتمع المدني في الحياة السياسية الليبية؟

\section{أهمية الدراسة:}

$$
\text { يمكن إبراز أهمية الدراسة الحالية على النحو النالي: }
$$

1ـ هذه الدر اسـة تعتبر دراسة استكثـافية تسعى إلى رصد ظـاهرة وتحديد معالمها و هي المتعلقة بدور الأحز اب السياسية ومنظمات المجتمع المدني و أدو اتهما لتنشكيل النظام السياسي في ليييا.

2-هي تفسيرية تحدد العلاقة بين المتغيرات الظاهرة وتطور اتها أو تحديدا بين طبيعة عمل النخبة السياسية وبين الأدوات المختلفة التي تستخدمها للمشاركة في الحياة السياسية للاولة. 
3- هي تقييمية تسعى إلى تقييم متغير ات العلاقة على نحو يحقق دور فاعل لسياسة للدولة.

أهداف الار اسة:

$$
\text { 1 التعرف على نشأة الأحز اب السياسية في ليبيا. }
$$

2-توضيح خريطة الأحزاب الاسلامية المنخرطة في الحياة السياسية اللبيية.

3-محاولة إبراز دور الأحز اب المدنية في الحياة السياسية الليبية.

4-الوقوف عند واقع منظمات المجتمع المدني في الحياة السياسية الليبية.

\section{منهج الدراسة:}

تستخدم الدر اسة المنهج الاستقر ائي الوصفي، والمنهج التحليلي النقدي، وذللك لفهم ودراسـة ووصف وتحليل دور الأحزاب السياسية و ومنظمات المجتمع المدني و أدو اتهما في الحياة السياسية الليبية.

\section{تقسيم الدراسة:}

يمكن تقسيم الدر اسة على النحو التالي:

المبحث الأول: نشأة الأحز اب السياسية في لليبيا.

المبحث الثاني: الأحز اب الإسلامية المنخرطة في الحياة السياسية اللايية.

المبحث الثالث: الأحز اب المدنية ودور ها في الحياة السياسية الليبية.

المبحث الر ابع: و اقع منظمات المجتمع المدني في الحياة السياسية الليبية.

$$
\text { تنائج الدر اسذة. }
$$

نشأة الأحزاب السياسية فى ليبيا 
بعد اسـاط نظـام القذافي تأسسـت عشر ات الأحز اب السياسية مـن مختلف التيـار ات الإسـلامية و الليبر اليـة والقوميـة و الملكيـة و المناطقيـة وغير هـا، وذلك في ظل سـي المجلس الوطني الانتقـالي لتأسبس بنيـة تشـريعية للأحز اب، مـن خـلال إصـار قانون تنظيم الأحز اب السياسية رقم 29 بسنة 2012 في 2 مايو 2012 إضافة إلى القانون بشأن ضوابط الكيانات السياسية رقم 30 لسنة 2012 الذي صدر في 24 ابريل 2012 و هما المنظمان لنشاط الأحز اب و الكيانات السياسية [3].

كانت المسودة الأولى لقانون الأحزاب تحظر قيام الحزب على أسـاس قبلي أو جهوي أو عرفي أو لغوي أو ديني، ولكن الجماعات الإسلامية واجهت هذا المشروع بالرفض، و هو ما أدى إلى اسقاط شرط عدم التمبيز، بما فتح المجال لأحز اب على أسس دينية ومناطقية وجهوية.

كما نجح الإسلاميون في الضـط على المجلس فجاء القانون ليحظر تداول أب فكر مخالف للشريعة وهو نص كان يستهدف حظر أية أحزاب ذات توجه علماني إضافة إلى ما نص عليه من حظر تداول أو نشر ما يخالف الثريعة [4]، وهو مـا يفتح الباب واسعا لتأويلات تضع قيودا على حرية التعبير، ويعمق من أزمة المرحلة الانتقالية في ليبيا، وفيما يلي استعر اض لأهم الأحزاب التي ظهرت بعد ثورة 17 فبر اير 2011.

المبحث الثانى

\section{الأحزاب الإسلامية المنخرطة فى الحياة السياسية الليبية}

ثمة نمطان من التيار ات الإسلامية في ليبيا، أحدهما انخرط في العمل السياسي الحزبي، والآخر ذو الصبغة السلفية الجهاديـة الذي يعد من أبرز الأحزاب الإسلامية [5]، و هذا ما سأتناوله في هذا المبحث مع تبيان نظرة الشريعة الإسلامية في مسألة الأحزاب السياسية.

\section{أولا- خارطة الأحزاب الاسلامية في ليبيا:}

أخذت أشكال متعددة من حيث التوجهات و الرؤى وكان لها دور في المرحلة الانتقالية.

- حزب العدالة والبناء، وهو الجناح السياسي لجماعة الإخوان المسلمين، وبدأ نشاطها في ليبيا في العام 1949، غير أنه اصطدمت بنظام القذافي حيث تعرض قياداتها للاعتقال، إلا أنها فاوضته منذ العام 2007 مع "سيف الإسلام القذافي"، وتؤمن الجماعـة بأن الإسـلام دين ودولة وغايتها إقامة نظام البـلامي، وسـاندت الجماعـة ثورة فبراير مـع انطلاقتها، وكان لها حضور في المجلس الوطني الانتقالي الليبي عام 2011.

إن الظروف السياسية و الاقتصادية في ليبيا إبان عهد القذافي لم تسمح للجماعة بالممارسة السياسية، و هو ما يفسر ضسف الأداء 
حزب البناء والعدالة سوى على 17 مقعداً في انتخابات المؤتمر الوطني العام في يوليو 2012 ليحل في المرتبة الثانية، بعد تحالف القوى الوطنية الذي حصد 39 مقعداً، وفي انتخابات يونيو 2014، حصل على 23 مقعداً.

استطاعت الجماعة عبر صياغة تكتل في المؤتمر الوطني مـع كتلة الثــداء الإسـلامية التي تضم إسـلامبين مستقلين، تمرير قانون العزل السياسـي لتقليص قوة التيـار ات المدنية، في مقابل زيادة قوتها في السلطة الانتقالية، حيث إن ثمـة مؤشر ات على علاقات تنسيقية في المو اقف الإقليمية و الدولية [6].

ـ حركة التجمع الإسلامي، تكونت الحركة في البدء من مجموعة من الملتزمين إسلامياً المنضمين سـابقاً إلى الإخوان المسلمين، قبل أن تحدث بينهما خلافات تنظيمية أدت إلى الانفصال وتأسيس حركة التجمع الإسلامية على أنها نمط من التنظيمات الجبهوية التي تسعى إلى جمع أكبر عدد من الإسـاميين بدون فرض قيود تنظيمية، وبدون الارتباط بأي تتظيم إسـامي خـارج البلاد، وبعد الثورة أنشـأت الجماعة حزباً سياسياً حمل اسم "رسالة"، واستطاع أن يتحصل في انتخابات المؤتمر الوطني العام على مقعد واحد.

ـ أحزاب ذات طابع سلفي منبثقة عن الحركة الإسلامية للتغيير، و هي حلت محل الجماعة الليبية المقاتلة بعد عمل مر اجعات لنبذ العنف إبان حكم القذافي في العام 2011، لكن أعضاءها شاركو ا بفعالية في محاربة كتائب القذافي إبان ثورة فبر اير 2011 بسبب خبرتهم في الجهاد الأفغاني. [7]

بعد الثورة تحولت الجماعة المقاتلة إلى "الحركة الإسـامية للتغيير" و انخرط بعض المنتمين لها في العمل السياسي عبر عدة أحز اب سياسية في الانتخابات التشريعية في يوليو 2012، من أبرز هم: حزب الوطن المعتدل ذي القاعدة الواسعة الذي ير أسـه "عبد الحكيم بلحاج" و"حزب الأمسة الوسط" الأكثر تشدداً في رؤاه الدينية تحت قيادة "سـامي السـاعدي" الذي يعد المنظر الرئيسي للجماعـة المقاتلة، و انضم أيضاً "عبد الو هاب الغايد" ـشقيق الر احل أبو يحيى الليبي الذي يعتبر على نطاق واسـع الرجل الثاني في تنظيم القاعدةالذي ترشح ونجح في الانتخابات البرلمانية في مدينة مرزق الجنوبية في انتخابات 2012، ويرجع ضعف الأحز اب المعبرة عن الاتجاه السلفي إلى طبيعة البنية الصوفية السنوسية التي تأسست عليها حركة التدين في ليبيا والتي لا تز ال حاضرة بقوة لدى كافة التيار ات بمـا فيها التيار المدني.

ـ أحزاب إسلامية أخرى تعبر عن امتدادات إقليمية، ومن أبرز نماذجها، التجمع الوطني من أجل الحريـة والعدالة و التنمية، وهو حزب سياسي إسلامي أسسه د. "على الصلابي" ويدعو إلى ديمقر اطية إسلامية، على غرار النموذج التركي [8]. ثانيا- الأحزاب السياسية في الثريعة الإسلامية: يمكن حصر الرؤية الإسلامية للتعددية الحزبية في إطار الدولة الإسلامية في اتجاهات ثلاثة: 


\section{الأول- إباحتها مطلَقًا:}

و هـو اتجـاه لايقف ـكمـا يقول الدكتور صـلاح الصـاوي- "عند حدود التعدديـة الملتزمـة بسـيادة الثـريعة؛ بـل يفتح البـاب على مصر اعيه، يرى أن المذهبية الإسلامية تستو عب إطلاق التعددية إلى أبعد مدى حتى تشمل الأحزاب الشيو عية الإلحادية و العلمانية ونحوه. فهو اتجاه يكاد يكون علمانيا في هذه المسألة؛ فلا فرق البتََّ بينه وبين الاتجاه العلماني فيها، و لاشك أنه تيار ضعيف في الصف الإسـامي، فضلا عن أنه مرفوض تماما من قبل من يمنلون أغلبية التيار الإسلامي، وإن كان من حجتهم ـكما يقول الدكتور صـلاح الصـاوي- "أن المذهبية الإسلامية التي استو عبت في داخلها المجوس و هم عبدة النار، و استو عبت في داخلها عبدة الأصنام عند كثير من أهل العلم، كما استو عبت اليهود و النصـارى لهـي مـن المرونـة بحيث تستو عب داخل إطار هـا الثـيو عيين و العلمـانيين؛ إذ لن يكونـوا أكفر من اليهود و النصارى و المجوس، وفي الصحيفة التي عقدها رسول الله ـ صلى الله عليه وسلم ـ مع أهل المدينة من المسلمين و اليهود ومن دخل في عهده معبرة ومنهاج، وسابقة لها دلالتها الحضارية التي تشهد بمدى مرونة الإطار السياسي في الدولة الإسلامية" [9].

\section{الثاني- منعها مطلَقا:}

الأحز اب لم تذكر في النصوص الثر عية إلا مقترنة بالذم والوعيد، و اقتصرت الإشارة بها إلى أعداء الدين، وفي المقابل لم يشر إلى جماعة المسلمين بتعبير الأحزاب قط، وإن ما أثنير إليهم بصيغة المفرد على أنهم حزب الله، وذلك في موضعين اثنين في القرآن الكريخ؛ فدل ذللك على أن المذهبية الإسـامية لاتتسع إلا لحزب واحد فقط هو حزب الله، أمـا الأحز اب فهي تعبيري تسع لجميع الفرق والنحل الخارجة عن جماعة المسلمين.

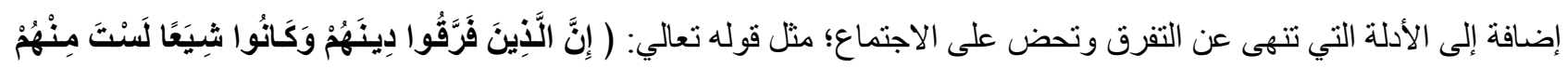

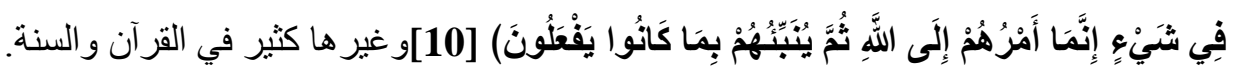

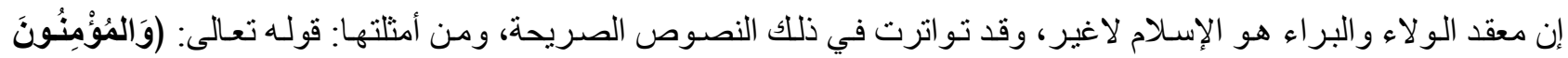

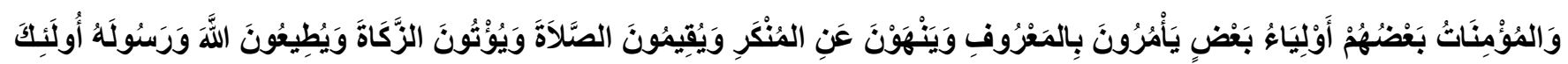

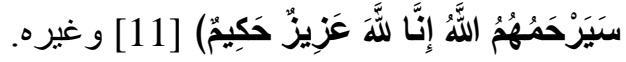
الثالث- إباحتها بشروط ضمن السياسة الشرعية: 1- السياسة الثر عية؛ أي تدبير الثئون العامة للدولة الإسلامية بما يكفل تحقيق المصالح ودفع المضار بما لا ينعدى حدود الثريعة و أصولها الكلية، و إن لم يسبق إلى القول بها لائمة المجتهدون؛ فهي متابعة السـلف الصـالح في مر اعاة المصـالح ومسـايرة الحوادث وفق القاعدة "سلفية المنهج وعصرية المو اجهة" مادام الأمر لم يخرج عن قو انين الثريعة الكلية ولم يصطلم بأصل كلي أو جزئي، و المر اد 
شئون العامة للدولة كل ما تتطلبه حياتها من نظم سواء كانت دستورية أم تشريعية أم قضائية أم تنفيذية، وسواء أكانت من شئونها الداخلية أم من علاقاتها الخارجية، فتدبير هذه الشئون و النظر في أساسها ووضع قو اعدها بما يتفق و أصول الشرع هو السياسة الشرعية. 2- الأصل في العقود والمعاملات الإباحة حتى يأتي مايدل على التحريم، وهذا هو أحد الر أي ينفي هذه المسألة، وهو الذي انتصر له عدد كبير من أهل العلم منهم شيخ الإسلام ابن تيمية في الفتاوى وغيره، وهو الأليق بمقاصد الثرع والأقوم بمصالح المكلفين، و إذا كان ذلك كذلك وكان ترتيبا لأسـاليب الأزمـة لوضـع المبادئ الإسـلامية في بـاب سياسـة الدولة موضعا لتنفيذ من بـابي العـادات والعقود كان الأصل فيه هو الحلال حتى يأتي مايدل على التحريم. فإذا استخلصنا صياغة لتعددية حزبية تحقق المصلحة وتفي بالحاجة، وتصون الأمـة من جور الحكام المستبدين، وتحفظ له حقوقها في الرقابة والحسبة، ولم تصطدم هذه الصياغة بم حكم في الشريعة سواء كان نصسا جزئيا أو قاعدة كلية فإن الأصل فيه هو الحلال، وعلى مدعي المنع إقامة الدليل. 3- ما لايتم الو اجب به فهو واجب؛ فإذا استصحبنا هذه القاعدة لتطبيقها في مجال السياسة والحكم، لوجدنا أن الثريعة تأمرنا بجملة

من المبادئ الكلية يتوقف وجوده أو حسن القيام بها في واقعنا المعاصر على التعددية السياسية ذلك؛ كالثورى، والرقابة على السلطة. 4- قاعدة الذر ائع والنظر إلى المآلات؛ فموارد الأحكام قسمان: مقاصد: و هي الأمور المكونة للمصالح و المفاسد في أنفسها، أي التي تعد في ذاتها مصالح أو مفاسد. ووسائل: وهي الطرق المفضية إليها، وحكمها حكم ما أفضت إليه من تحليل أو تحريم. والأصل في اعتبار الذرائع هو النظر إلى مآلات الأفعال ولاغنى للفقبه من النظر في مآلات الأقو ال والأعمال قبل إجراء الأحكام فقد يكون الشيء مشروعا ولكني منع باعتبار مآله، وقد يكون غير مشروع ويترخص فيه باعتبار مآله. 5- صيانة الحقوق والحريات العامة، إذا رأت الأمـة المظالم و لا يتأتى تحقيق مقصود الثـار ع في صيانة الحريات إلا بإنشـاء هذه التكتلات الشعبية التي تحمى الفرد من عسف السلطة وجور الحكام، وتحقق لها لسيادة على نفسهـ و على قراره في إطـار سيادة الثريعة، و لا قبل للفرد الأعزل بـالوقوف من فردٍ أمسام استبداد السلطة، ولايتسنى لله ممارسـة حقه في النقد والحسبة إلا من خـلال إطسار سياسي يكتسب من خلالـه قوة الاجتمـاع، وينظم هذه الآر اء المبثوثنة بين الأمسة كأفر اد لتجد طريقه إلى الر أبي العـام، ومن خلاله إلى مو اقع المسئولين.

6- السو ابق التاريخية؛ حيث يستشهد بعض الذين يقولون بمشروعية التعددية السياسية بأن التاريخ الإسـلامي شهد هذه التعدديـة في صورة الفرق الإسلامية؛ كالخوارج، والمعتزلة، والثيعة والمرجئة، ونحو هم، فهي تكتلات سياسية في الأصل، تحزبت حول اختيارات وبر امج سياسية، وإن كانت قد كست تحزبها السياسي لبوس الاختلاف العقدي و المو اقف الدينية. المبحث الثالث الأحزاب المدنية ودورها في الحياة السياسية الليبية 
ظهرت عقب إصدار الإعلان الدستوري من قبل المجلس الوطني الانتقالي العديد من التيارات والأحز اب السياسية التي كان لها دور في الحياة السياسية الليبية وهي:

ـ تحسالف القوى الوطنية، وهو القوة الأهم والأكثر تأثثير ا على صعيد الأحزاب في ليبيا، وتأسس في فبراير 2012 من مجموعة أحز اب وجمعيات أهلية، وتبنى التحالف أفكارًا ليبر الية تنادي بالمو اطنة و الديمقر اطية وحقوق الإنسان، وفي ذات الوقت قدم رؤيـة معتدلة للإسلام و الدولة المدنية، و أصبح التحالف لاعباً رئيسياً في الصر اعات الداخلية في ليبيا بعد أن حصد 39 مقعداً في انتخابات المؤتمر الوطني العام يوليو 2012، متقدماً بذلك على الإسلاميين و50 مقعداً في انتخابات 2014. أظهر تحالف القوى الوطنية منذ إعلان تأسيسه العديد من المواقف، منها معارضته لأداء المجلس الوطني الانتقالي و الحكومـة الانتقالية، حيث شن عليهما هجوماً حاداً و أعتبر أن أداءهما لم يتفق مع التوقعات المشروعة لأبناء ليبيا [12]. ـ كيانات وأحزاب قومية ومناطقية ومستقلون، نظر أ لطبيعة النظام الانتخـــابي الذي يحول دون سبطرة حزب تكون لـه الأغلبية، برزت أحـز اب صـغيرة ذات بعد قومي ومناطقـي، ومنهـا حزب الجبهة الوطنيـة للإنقاذ، أكبر التنظيمات السياسية المعارضـة لنظـام القذافي خلا عقدي الثمانينيات والتسعينيات، والتيار الوطني الوسطي بقيادة د. "على الترهوني" وزير النفط والمالية في أول حكومـة بعد الثورة، وأيضاً الاتحاد من أجل الوطن الذي أسسه د."عبد الرحمن السويحلي".

بالإضافة إلى ذلك هناللك عدة أحز اب صغيرة عادة ما تحصل على معدل مقعد للكل منها، وهي: الحكمة، و الرسالة، والوطن، و الوطن للتنمية و الرفاه، وتيار شباب الوسط، ولبيك وطني، والحزب الوطني الليبي، والركيزة، و الوطن و النماء، و التجمع الوطني بوادي الثشاطئ، وتحالف وادي الحياة، والقائمة الليبية للحرية والتنمية، وكتلة الأحز اب الوطنية، وتجمع الأمة الوسط، وليبيا الأمل [13]. بشكل عام يمكن القول إن الأحز اب الليبية عموما تعاني الكثير من النو اقص و التحديات التي تعكس ضعف الفاعلين الاجتمـاعيين بشكل عام فهي تعاني ضعفا تنظيميا وربما عجز ا ديمقر اطيا في إدارتها إلا أن أهم خصائصـها هو الافتقار لمشروع سياسي و إلى قاعدة اجتماعية حقيقية و الاعنماد على الثعار ات و التحريض و الثعبوية العدمية وهو ما يعتبر خاصية تشترك فيها الأحزاب الليبية مع مثنلاتها في دول الانتقال الديمقر اطي العربية. العديد من أحز اب ليبيا الجديدة، وربما باستثناء تحالف القوى الوطنية (الليبر الي) ويضم عددا كبير ا من الأحزاب و التنظيمات، أو حزب الجبهة الوطنية (وريث الجبهة الوطنية لإنقاذ ليبيا التي تأسست في الثمانينات لمعارضـة القذافي) وحزب العدالـة والبناء الخـاص بجماعة الإخوان المسلمين لا تعدو في الو اقع عن أن تكون تجمّعات لأعداد محدودة من الأفراد الذين يندر أن يتمتع أحدهم بمقوّمات زعامة من أي نوع [14]. 
بالتالي فالمتتبع للنشاط المتعلق بإعلان تأسيس الأحز اب يمكنه استخلاص الغموض و عدم الوضوح فيما يتعلق بهذه المحاو لات، و افتقار ها إلى القدرة على إعلان بر امج سياسية محددة وتحديد هويتها السياسية وموقفها من القضايا الر اهنة.

إن الأحز اب التي نشأت حديثا عكست ديناميـة تنافسية أثناء الانتخابـات أدت إلى تعقيد المشهـ وجعلت الوصـول إلى توافقات وتسويات غير ممكن، ذلك أن هذه الأحزاب حرصت على تعظيم مكاسبها في ظل خوفها من أن تدفعها الأحز اب الأخرى خارج سـاحة المنافسة و الحكم، ويزيد من خطورة التأثير ات السلبية لو اقع الحياة الحزبية الحاليـة أنها خلقت استقطاب حاد في الر أبي العام وبين النخب المختلفة وأدت لجعل التوصل لتو افقات في المرحلة الانتقالية أمرا غايـة في الصعوبة وهو مـا أدخل البلاد دوامـة الصر اع وسط تدهور الوضع الأمني.

على غرار جدل الأحز اب السياسية، فإن قانون الانتخابـات في ليبيا تعرض هو الأخر لصر اعات عديدة حوله خاصـة في ظل المخـاوف من تهميش الأحز اب المناطقيـة وفئات أخرى كالمر أة، وبالتـالي كان الهدف من القانون عدم إيجاد قوة مهيمنة على المشهـ السياسي ولذا اقترح القانون نظاما انتخابياً مركباً، حيث يشغل 120 من المقاعد الــ 200 في البرلمـان عبر النظام الأكثر ومن مرشحين

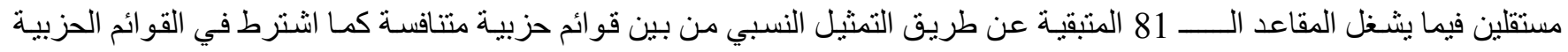
تناوب المرشحين من الذكور و الإناث، ورغم أن النظام الانتخـابي كرس التعددية السياسية وضمان عدم بروز قوة مركزيـة سياسية في ليبيا إلا أنه بالمقابل لهيمنة الدور القبلي والعشائري [15].

\section{المبحث الرابع}

\section{و اقع منظمات المجتمع المدنى في الحياة السياسية الليبية}

شهدت ليبيا بعد الاستقلال عام 1951 إصدار عدد من القوانين التي نظمت العمل الأهلي، ونم إنشاء عدد من الجمعيات المتمثلة في الجمعيات العاملة في مجال رعاية الأسرة وكفالة اليتيم وتعليم المر أة ومحو الأميـة بالإضـافة إلى الأنديـة الرياضية و الحركة الكثفية ونقابات العمال و غير ها [16].

مع بدايات الستينيات ساهم اكتثاف النفط انتشار التعليم وافتتاح الجامعة الليبية والاتسـاع في عدد الصحف اليومية والأسبو عية ووسـائل الإعـلام المسموعة، في انتشـار نقافة العمل الأهلي ممـا سـاعد على اتسـاع رقعـة هـامش حريـة الأنشطة الاجنماعية والتربويـة و الرياضية و الكثنفية. 
كانت الدولة تقوم بدعم هذه الأنشطة مادياً وفق لو ائح تتظيميـة، وكان السباق على أشده بين هذه المؤسسـات التي كانت تسعى جاهدة للوصول إلى المر اتب الأولى التي تضمن لها المكاسب المعنوية والدعم المـالي المضـاعف الذي يسـاعدها على الاستمرار في أداء مهامها [17].]. في سنة 1970م صدر القانون رقم "111" بشأن الجمعيات، وتو اصل العمل بهذا القانون حتى سنة 2001م عندما صدر القانون المعروف برقم "10" بشأن إعادة تنظيم الجمعيات الأهلية، ولكنه كان يضم العديد من المواد التي تضع المزيد من الصعوبات و العر اقيل أمام العمل الأهلي، في ظل وضع عدد من الثروط المتعلقة بـعدد المؤسسين للجمعية، ومقر الجمعية، ووقف الدعم الحكومي وفتح المجال للاستثمار ، وتدخل اللجنة الثعبية العامة (رئاسة مجلس الوزر اء)، وضرورة الحصول على الموافقة الأمنية، وغيرها. [18] بذللك فقد عانت مؤسسات المجتمع المدني في ليبيا وكل أنماط ومستويات العمل الأهلي من هيمنة الدولة وتسلطها منذ العام 2001 تحديداً، ولم تحتل هذه المؤسسات أي فضاء مستقل ومنفصل عن الدولة بل إنها اعتبرت جزءاً من آليات النظام السياسي، وعملت المنظمات المدنية على حمايـة وتلميع النظام السـابق، في ظل الرقابـة الثديدة والسبطرة الأمنيـة التي قضت على كل المبادرات أو أيـة نشاطات أخرى لدرجة انعدام الجرأة والخوف الثديد من ذكر كلمة اجتماع لجمعية أو مبادرة وإنما كان يتم استخدام كلمة لقاء. و عقب ثورة فبر اير عام 2011، ظهرت عدة محاو لات لتأسيس قانون جديد للمنظمات يؤكد على استقلالية المجتمع المدني وحياديته وعدم احتواء السلطات التنفيذيـة لـه، ويمنح المنظمـات حق التقاضـي والطعن في القوانين و القرار ات و الترشيحات من حيث دستوريتها أو تو افقها مع الأهداف الني أنشئت من أجلها تلك المنظمات، كما يمنح للمنظمات المعنية بالثفافية حق التفتيش و الاطلاع على سجلات وتقارير الثركات و المصالح الحكومية. على هذا تمكن عدد كبير من الجمعيات الأهلية من تنظيم مبادرات إغاثية خيريـة وتقديم الدعم الطـارئ من المسـاعدات الطبية و المو اد الغذائية و الطرود التموينية، ونشطت الجمعيات الخيرية والإنسانية وجمعيات الدعم النفسي والاجتماعي والتأهيلي بسبب كثرة عدد الجرحى و الثهداء.

تتنامى يومياً تقريباً عملية ولادة منظمات المجتمع المدني في كل المدن الرئيسية في ليبيا، تتمحور هذه التنظيمات على قضـايا و انشغالات أغلبها حقوقي أو نسائي أو إنساني الطابع، وبينما يبدو واضحاً التواجد النشط للتيارات الإسـلامية في عدد كبير منها، فإن التيار ات الأخرى تجد تمثيلاً مناسباً أيضاً، وبينما تحفل شبكات التو اصل الاجتماعي المعروفة بأعداد متتاميـة من المجمو عات و الثبكات، فإن حقيقة كون غياب النتظيم وغياب السلطة الفاعلة في البلد يجعل من هذه الظاهرة أمراً مرتبطاً بما يجري أكثر من كونها تعبيراً عن ظاهرة متأصلة في الثقافة الداعمة للمجتمع المدني. 
عقب إعـلان التحرير في 23 أكتوبر 2011 نحولت اهتمامـات المنظمـات والجمعيات واضعة نصب عينيها طبيعـة المرحلة

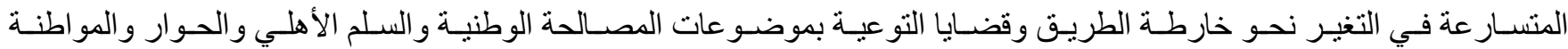
و الديمقر اطية و العدالة الانتقالية وحقوق الإنسان و الثفافية وقضايا المركزية و اللامركزية و الفيدر الية. بالإضـافة إلى دعم وتقويـة مشـاركة المر أة والثباب في الحر الك السياسـي والاهتمـام بموضـوع انتخابـات المؤتمر الوطني العام وصياغة الدستور و غير ها من الشؤون المتعلقة ببر امج المعاقين وكذلك شؤون اللاجئين النازحين و المهرين و المفقودين. اختلفت قوة منظمات المجتمع المدني والجمعيات باختلاف المواقع الجغر افية وبحسب تواريخ سقوط قوات نظام القذافي السابق في هذه المناطق، بالإضافة إلى نسبة الولاء لهذا النظام في هذه المناطق. مثلا بر هنت هذه الجمعيات و المنظمات عن قوتها وفاعليتها في مدن بنغازي ومصر اته والزاوية كونهار رموز الثورة والمقاومـة بالإضافة لكونها تجمعات سكانية كبيرة وفيها الثقل السياسي والإقتصادي، ومن ثم لحقت بها مدينة طر ابلس ذات الكثافة السكانية الأكبر عدداً كونها العاصمة على اختلاف مكوناتها القبلية والأثنية ونو اجد القرار السياسي و التشريعي فيها. أما مناطق الجنوب و الوسط تفاوتت فيها قوة منظمات المجتمع المدني والجمعيات مثل سبها و الكفرة، بينما ظهرت ضعيفة أحيانا في بعض المناطق مثل تر هونة وسرت وبني وليد، في حين بدت هذه المنظمات و الجمعيات نشيطة وقويـة في جبل نفوسـة الذي يقطنه غالبية الأمازيغ الليبيين.

ظهر الخلط بين مفاهيم منظمات المجتمع المدني وتداخلها بالكيانات السياسية والأحزاب السياسية والتحالفات السياسية من خلال رغبـة العديد من مؤسسـي هذه الجمعيـات و المنظمـات بالانتمـاء إلى كيان أو حزب سياسـي وبنفس الوقت المشـاركة في الرقابـة على الانتخابـات، و هذا الخليط المعقد نـاتج عن عدم الخبرة والمهنيـة بسب العقود الأربعـة الماضية وحداثـة التجربـة في المشـاركة السياسية والمدنية.

من ثم يمكن لذلك فأن غياب هذا المكون في ليبيا يجعل عملية الانتقال الديمقر اطي أكثر عرضـة للفشـل في تحقيق أب مستوى مطلوب، وخاصة في ظل التحديات و العو ائق التي تواجه المجتمع المدني في ليبيا، و على رأسها ضـف القدر ات المالية و التنظيمية و غلبة الطابع الجهوي أو المحلي و التنوع و التناقض في وجهات النظر التي تتبناهـا تنظيماتـه المختلفة إضـافة إلى أن كثير من التنظيمات التي نشأت تعرضت للتشرذم و الانقسامات و الانشقاقات بما يعكس عدم القرة على تبني و استيعاب الرؤى المختلفة بل أن كثير ا من المنظمات ظهرت كفقاعات سر عان ما اختفت سريعا. 
خاصة أنه ليس هناك اتفاق على تحديد دور وطريقة مشاركة المجتمع المدني في تقرير حاضر ومستقبل ليبيا، وتظل الجمعيات الأهلية في كثير من الحالات معتمدة على الإدعاء بشر عية اكتسبتها أثناء الثورة في نظر السكان، فالجمعيات التي نشأت أيام الصر اع تحرص على استثمار هذه الثرعية و هو ما خلق دينامية صر اعية في علاقات الجمعيات بعضها البعض.

مع أنه تم الإعلان عن تشكيل اتحاد لمنظمـات المجتمع المدني فإن الو اقع يبين أنه لا يعبر عن اسمه تمامـا، خاصـة وأن عدد الجمعيات التي كونته ليس كبير اً، و لا تواجد له في كل مناطق ليبيا، وهو ما يعكس أسلوب المبادرة والسعي إلى السيطرة بتكوين تجمعات و اتحادات بدون أن يكون لها ترجمة عملية على المستوى الثعبي في كل أرجاء البلاد.

إن هذا يصدق أيضاً على تجمعات نقابيـة أو دينيـة كرابطة أو اتحاد علماء ليبيا و اتحاد الطلبة وغير همـا، هناك شعور بمبادرة قوى إسلامية أساساً بتكوين هذه التنظيمات و إحكام السيطرة عليها، ييرز هذا أيضاً من خلال قيام التيار الإسلامي بتأسيس جمعيات خيريـة أو إنسانية بذات الأسلوب المُسيس.

حيث تقوم الجمعيات المرتبطة بالأحز اب بثكل خاص باستخدام هذه الأداة وهو مـا يتسبب في تسبيس المجتمع المدني وجعله يدخل دائرة الصر اع الحزبي، و هو ما يحول دون نشوء أي كتلة مؤثرة في قرار السياسي ولا يجعل المجتمع المدني المستقل قادر على منافسة المنظمات التي لديها موارد مادية وشر عية ثورية أيضا.

في الوقت الذي أقتصر فيه دور مفوضية المجتمع المدني بالمجلس الوطني الاتتقالي على إنشـاء صندوق لدعم المجتمع المدني يتبع ما يعرف بالآلية المالية المؤقتة، تبرز خطورة أية محاو لات تقوم بها تيار ات سياسية وحزبية في استخدام مؤسسات المجتمع المدني واستغلالها لأغر اضها.

إن من شأن ذلك أن يلقى بهذه المؤسسات الوليدة والحديثة إلى المجهول، ويجعل القبلية تستحوذ على الاهتمام وتصبح محوراً للعمل السياسي بما له صلة بالجهوية وخطر ذلك على الهوية والاندماج والوحدة الوطنية و العملية الديمقراطية، لذا سيكون هناك تحدِّ أمسام التيار ات الإسلامية وهو مدى قدر اتها على تسهيل عملية الاتتقال الديمقر اطي من خلال عملها على تحرير مشـاعر واتجاهـات الأفراد من هيمنة الدولة، وأن يؤدي ذللك على خلق مجال واسع للاديمقراطية بدون أن يمنع تحقيق الديمقر اطية ذاتها.

\section{نتائج الدراسةة:}

من خلال ما تقلام يمكن استخلاص أهم النتائج و المتمثلة في:

1 ـأكدت الدر اسة إن حقبة نظام القذافي ارتكزت حول الاستئنار بالسلطة من خلال التحكم و السيطرة في منظومـة وسـائل وقنوات التنشئة

الاجتماعية و السياسية وتوظيفها في اتجـاه يخدم أهدافها ومصـالحها المتمنلـة في المحافظة على واقع سياسي يكرس هيمنتها وديمومـة 
وجودها السياسي، ومن ضمن هذه المحتويات التعبيرات التي جاء بها القذافي في كتابه الأخضر ، مثل: التمثيل تدجيل، الحزبيـة إجهاض للايمقر اطية.

2-عقب ثورة فبر اير الليبية تم تشكيل عدد كبير من منظمـات المجتمع المدني لكنها لا تز ال محدودة النشـاط ونو اجدها ضـعيف في بقيـة مناطق لبييا، و هو مـا يعكس أسلوب المبادرة والسـي إلى السبطرة بتكوين تجمعات و اتحـادات بدون أن يكون لها ترجمـة عملية على المستوى الشعبي في كل أرجاء البلاد. 3- كثفت الدر اسة على الرؤية الإسلامية للتعددية الحزبية في إطار الدولة في اتجاهات ثلاثة، المتمنلة في: إباحتها مطلَقًا، أو منعها مطلَقا، أو إباحتها بشروط ضمن السياسة الثر عية.

\section{توصيات الاراسة:}

بعد نهاية حكم "القذافي" تواجه ليبيا تحديا آخر هو بناء دولة جديدة فيها دستور تستند فيها على الأسس القانونية والثرعية و إقامة نظام مؤسسات لإدارة شؤون البلاد وبناء نظام سياسي و اقتصادي واجتماعي جديد، وبناء على ذلك يوصي الباحث على الآتي: 1 -العمل على بناء دولة ديمقر اطية ـ إسلامية وسطية ـ مدنية ـ تعدديـة ـ لا تعادي المكونـات الاجتماعية والثقافية و القبلية، وذلك بتحكيم الإر ادة الثعبية في تحديد المرجعيات واختيار شكل الحكم وسلطاته، و الفصل فيما يعترض طريق القوى الوطنية من خلافات، دون ربط الرجوع لهذه الإر ادة بأي شروط، وتجنب تقديم أي مصلحة فئوية أو قبلية على هذه الإر ادة. 2-وضع ضو ابط دستورية للتشريعات القانونية ينظم عمل الأحزاب السياسية، ومؤسسات ومنظمات المجتمع المدني التي ينبغي أن تحوي أفر اد المجتمع كافة، بما يحول دون تعدي أي فرد أو أغلبية أو أقلية سياسية على حقوق الآخرين وحرياتهم.

3- يوصي الباحث بضرورة إعطاء جميع الليبيين حق المشاركة في هذا النظام الديمقراطي، بدون أي عزل سياسي أو تمييز سياسي أو اجتماعي، وعلى أساس حقوق المو اطنة الكاملة لليبين كافة، وذلك بالعمل على إعادة إصلاح وبناء المؤسسات الديمقر اطية الرسمية و غير الرسمية للدولة الليبية الحديثة، وإنجاز مهمة الوحدة الوطنية والاستقرار الأمني والمجتمعي، ساعين في ذلك المسـاهمة في تنميـة المجتمع الليبي.

4- يوصي الباحث على ضرورة العمل على تحقيق التحالف السياسي بين معظم الحركات و التيارات و الأحز اب الإسـامية ذات التوجهات المعندلة والتيار ات و الأحز اب المدنية، والتي تؤدي بدور ها إلى إندماج القوى اللبيية كافة في سبيل السعي نحو تحقيق وحدة الصف الليبي، و ون ثم تحقيق استقرار الدولة الليبية. 
قائمة المصادر والمراجع:

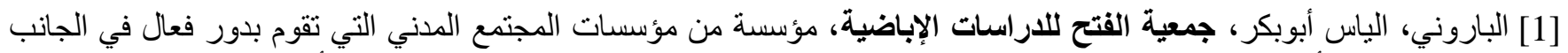

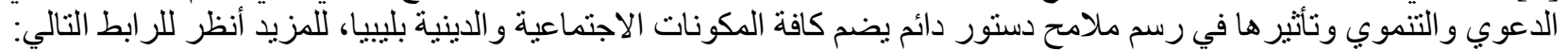

https://www.facebook.com/elyas.albarouni.1 [2] الباروني، إلياس أبوبكر، دور الحركات الإسلامية في الحكم الليبي اليوم، عبر نشرة الأخبار المسائية، قناة الميادين الفضـائية، من

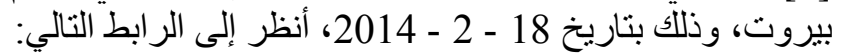
http://www.almayadeen.net/Newscast/AuH9NoOIlk6,_qLWAVAETg/8/2014-02-18

[3] حتيتة، عبد الستار، وصبري، مروي، خارطة الأحزاب السياسية في ليبيا.. معتدلة بملامح إسـلامية، جريدة الشرق الأوسط، العدد

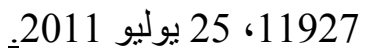
[4] خشيم، مصطفى عبد الله أبو القاسم، الأحزاب السياسية في ليبيا الجديدة بين النظرية والتطبيق، ليبيا المستقبل، 2012/4/25، على الر ابط: [5] الصالحي، الوليد، خليل جبارة، دراسة ميدانية لأوضاع واحتياجات منظمات المجتمع المدني في ليبيا... المجتمع المدني: الواقع

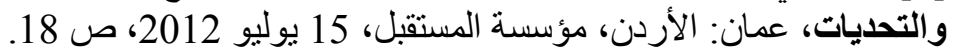

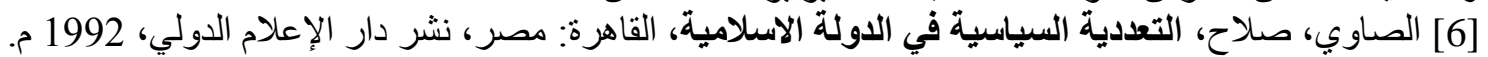

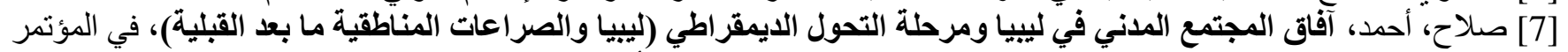

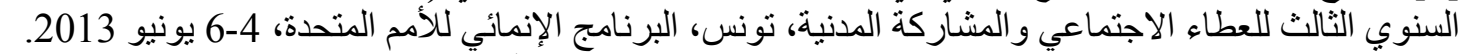

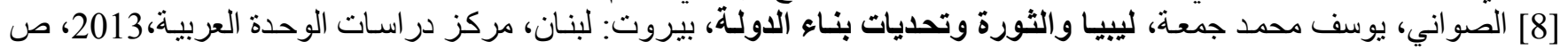

[9] فاعلية صدور قانون الأحزاب لأول مرة في ليبيا، 25 أبريل 2012، على الرابط:2http:/www.qurynanew.com/33683.

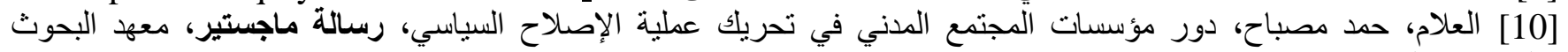
و الدر اسات العربية، 2012.

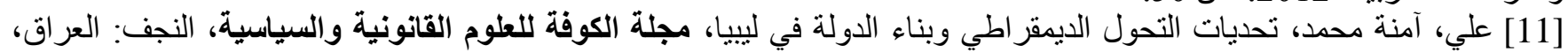

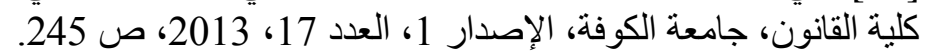

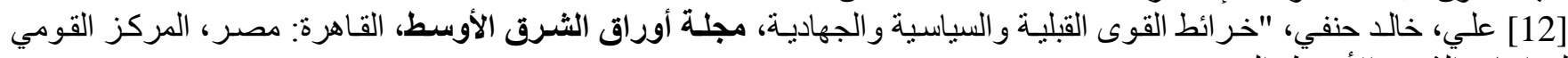

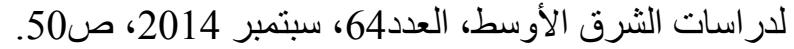
[13] عميش، إبر اهيم فتحي، التاريخ السياسي ومستقبل المجتمع المدني في ليبيا، بنغازي: ليبيا، برنيق للطباعة و الترجمة والنشر،

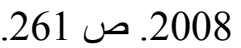
[14] فاعلية صدور قانون الأحزاب لأول مرة في ليبيا، 25 أبريل 2012، على الر ابط: http://www.qurynanew.com/33683 [15] قوي، بوحنية، المجتمع المدني بليبيا وموريتانيا: صراع القبيلة والدولة، العدد الثالث، الدوحة: قطر، مركز الجزيرة للدراسات، مايو 2014. [16631 الكوت، البشير، دور المجتمع المدني في بناء ليبيا الجديدة، ليبيا المستقبل، 2011/12/22، على الرابط: http://www.libya-al-mostakbal.org/news/clicked/16631 [17] المسماري، إدريس، رضا بن موسى، مؤسسات المجتمع المدني والثقافة في ليبيا، مجلة عراجين، القاهرة: مصر ، العدد الثامن، نوفمبر 2010. [18] ندوة حول مسودة قانون منظمات المجتمع المدني في ليبيا، ليبيا المستقبل، 2013/10/9، متاح على: mostakbal.org/news/clicked/39841 